\title{
What is the ideal timing for endoscopy in acute upper gastrointestinal bleeding?
}

\section{다)(1) $\Theta$}

\author{
Author \\ Alan Barkun \\ Institution \\ McGill University Health Centre - Division of \\ Gastroenterology, Montreal, Quebec, Canada \\ submitted 6.3.2017 \\ accepted after revision 20.3.2017 \\ Bibliography \\ DOI https://doi.org/10.1055/s-0043-107613 | \\ Endoscopy International Open 2017; 05: E387-E388
}

\author{
(c) Georg Thieme Verlag KG Stuttgart · New York \\ ISSN 2364-3722
}

Corresponding author

Alan Barkun, McGill University Health Centre - Division of Gastroenterology, 1650 Cedar Ave, Montreal, Quebec, H3A

1A1, Canada

Fax: +1-514-934-8547

alan.barkun@muhc.mcgill.ca
The performance of esophago-gastric-duodenoscopy (EGD) in patients presenting with acute upper gastrointestinal bleeding remains critical as this technology provides both diagnostic and therapeutic benefits, with endoscopic hemostasis remaining the cornerstone of therapy, especially in patients with non-variceal bleeding etiologies [1].

The timing of EGD in upper gastrointestinal bleeding remains somewhat controversial, especially considering disparate recommendations that suggest performing an early gastroscopy at varying time intervals following initial presentation [1 - 3]. In non-variceal bleeding, randomized clinical trial (RCT) data have suggested that EGD within 24 hours is as efficacious at improving outcomes as within shorter time frames ( 2 or 12 hours) $[1,4]$. However, recent observational data using exploratory analyses have suggested that an earlier gastroscopy may be beneficial in very acutely ill patients, swaying some guidelines to recommend earlier gastroscopy, within 12 hours (actually 13 hours reported in the study) [5]. This timing is also that proposed in variceal bleeding guidelines based on expert opinion [6]. The importance of the scheduling of EGD is further highlighted by the report of a weekend effect whereby the prognosis of patients presenting after hours may be worse, especially in non-expert centers, either because of patient selection or lack of timely resources and expertise [7].

Garg et al. add to the literature on this topic, having performed a large administrative database retrospective cohort analysis of 2066707 admissions to acute care hospitals for upper gastrointestinal bleeding, using information drawn from the American National Inpatient Sample from 2007 to 2013 [8]. The study population included mainly patients with non-variceal upper gastrointestinal bleeding, including $49 \%$ with bleed- ing ulcers, but also $12.4 \%$ of patients bleeding from esophageal varices. Unfortunately, the authors do not report endoscopy timing and outcomes stratified according to variceal or nonvariceal bleeding etiologies, nor were exploratory threshold analyses performed to attempt at better estimating the impact of adopting a 12-hour versus a 24-hour EGD timing following admission. Bearing in mind the retrospective study design with the attendant inevitable confounding, and thus the inability to conclude on causation, as we are reminded by the authors, the main conclusions of the inferential analyses suggest that early EGD is associated with lower morbidity and mortality compared to delayed EGD or no EGD. The overall costs, including the costs of the procedure, and length of hospital stay, were much higher in patients who did not undergo early EGD, and greater in the delayed EGD group as well. Some or all of these results have been proposed in previous contemporary observational studies [9-13], but the generalizability and precision of effect size estimates are enhanced in this study by the large patient sampling. Furthermore, patients who underwent early EGD had lower incidence of acute renal and respiratory failure.

Perhaps even more important are the descriptive prevalences. Indeed, it is reassuring (confirming other reports [14]) that the mortality of upper gastrointestinal bleeding has decreased compared to older reported estimates, approximating $4.3 \%$ in the current study (that also includes the small proportion of patients with variceal bleeding and its attendant much worse prognosis) [8]. It is somewhat disappointing, however, to note that, of the patients who underwent EGD, 1020744 were noted to have had an early EGD (within the first 24 hours), while 714372 had delayed EGD (>24 hours), i.e. a full $58.8 \%$ were not managed according to contemporary guidelines. Al- 
though there may be many reasons for such a delay, as reviewed by the authors, this proportion remains woefully low in light of the benefits of early endoscopy repeatedly reported by both RCT and observational studies. We are even further away from a 12-hour procedural threshold, although quality evidence for this earlier target as mentioned above is weaker.

Although the reported overall low mortality of acute upper gastrointestinal bleeding is encouraging and in keeping with other contemporary reports, this large retrospective cohort analysis again emphasizes the need for persistent lobbying in providing adequate timely resources and widespread adoption and implementation of a policy of early endoscopy as defined by a threshold within 24 hours of initial presentation. Additional high-quality data are required to further justify a shortening to within 12 hours amongst patients bleeding from non-variceal etiologies, with tailored studies further defining subgroups who may benefit most from such earlier intervention.

\section{Competing interests}

None

\section{References}

[1] Barkun AN, Bardou M, Kuipers EJ et al. International consensus recommendations on the management of patients with nonvariceal upper gastrointestinal bleeding. Ann Intern Med 2010; 152: 101 - 113

[2] NCGC. Acute upper gastrointestinal bleeding. Management. Clinical Guideline. Methods, evidence and recommendations, June 2012. Commissioned by the National Institute for Health and Clinical Excellence (NICE). National Clinical Guidance Centre, The Royal College of Physicians, London. Accessed at https://www.nice.org.uk/guidance/ cg141/evidence/full-guideline-186534541
[3] Laine L, Jensen DM. Management of patients with ulcer bleeding. Am J Gastroenterol 2012; 107: 345-360; quiz 361

[4] Laine L. Upper gastrointestinal bleeding due to a peptic ulcer. NEJM 2016; 375: 1198

[5] Lim LG, Ho KY, Chan YH et al. Urgent endoscopy is associated with lower mortality in high-risk but not low-risk nonvariceal upper gastrointestinal bleeding. Endoscopy 2011; 43: 300 -306

[6] Bari K, Garcia-Tsao G. Treatment of portal hypertension. World J Gastroenterol 2012; 18: $1166-1175$

[7] de Groot NL, Bosman JH, Siersema PD et al. Admission time is associated with outcome of upper gastrointestinal bleeding: results of a multicentre prospective cohort study. Aliment Pharmacol Ther 2012; 36: $477-484$

[8] Garg SK, Anugwom C, Campbell J et al. Early esophagogastroduodenoscopy is associated with better outcomes in upper gastrointestinal bleeding: a nationwide study. Endosc Int Open 2017; 05: E376-E386

[9] Wysocki JD, Srivastav S, Winstead NS. A nationwide analysis of risk factors for mortality and time to endoscopy in upper gastrointestinal haemorrhage. Aliment Pharmacol Ther 2012; 36: 30-36

[10] Jairath V, Kahan BC, Logan RF et al. Outcomes following acute nonvariceal upper gastrointestinal bleeding in relation to time to endoscopy: results from a nationwide study. Endoscopy 2012; 44: 723 - 730

[11] Abougergi MS, Travis AC, Saltzman JR. The in-hospital mortality rate for upper $\mathrm{Gl}$ hemorrhage has decreased over 2 decades in the United States: a nationwide analysis. Gastrointest Endosc 2015; 81: 882 888 , e1

[12] Hearnshaw SA, Logan RF, Lowe D et al. Use of endoscopy for management of acute upper gastrointestinal bleeding in the UK: results of a nationwide audit. Gut 2010; 59: 1022 - 1029

[13] Rosenstock S], Moller MH, Larsson $\mathrm{H}$ et al. Improving quality of care in peptic ulcer bleeding: nationwide cohort study of 13,498 consecutive patients in the Danish Clinical Register of Emergency Surgery. Am J Gastroenterol 2013; 108: 1449-1457

[14] Jairath V, Martel M, Logan RF et al. Why do mortality rates for nonvariceal upper gastrointestinal bleeding differ around the world? A systematic review of cohort studies Can J Gastroenterol 2012; 26: $537-543$ 